\title{
BALI - PUSAT FASHION NUSANTARA : MERUANGKAN WARISAN BUDAYA SEBAGAI SLOW FASHION
}

\author{
Felix Suanto $^{1)}$, Agustinus Sutanto ${ }^{2)}$ \\ 1)Program Studi S1 Arsitektur, Fakultas Teknik, Universitas Tarumanagara, \\ felix.315170007@stu.untar.ac.id \\ 2) Program Studi S1 Arsitektur, Fakultas Teknik, Universitas Tarumanagara, \\ berpikirteoripraksis@gmail.com
}

Masuk: 04-07-2021, revisi: 14-08-2021, diterima untuk diterbitkan: 23-10-2021

\begin{abstract}
Abstrak
Pakaian atau Fashion merupakan sebuah bagian dari 3 kebutuhan primer manusia yang merupakan sebuah syarat untuk bertahan hidup. Pada awalnya, pakaian merupakan sebuah objek yang diproduksi untuk memenuhi sebuah kebutuhan manusia; diproduksi secara sustainable, ecofriendly, ethical, dan green. Dan fenomena tersebut dinamakan Slow Fashion. Tetapi seiring perkembangan dunia tentang kecepatan dan percepatan (Dromologi), pada dunia fashion timbul fenomena baru, yakni Fast Fashion. Fast Fashion, sebuah produksi massal pakaian dengan harga murah dan kualitas sekali pakai. Fenomena ini mengubah consumerism dalam fashion industry, dimana dengan harga yang murah, konsumen dapat terus mengikuti perkembangan tren, serta membeli pakaian untuk hanya sekedar hobi. Dan hasilnya, kedua fenomena itu saling berkembang secara mutual dan memberikan dampak besar terhadap kondisi ekosistem kita sekarang; mulai dari polusi air yang dihasilkan dari limbah produksi, konsumsi air bersih dalam jumlah yang sangat besar, akumulasi limbah pakaian yang sudah tidak terpakai, hingga deforestasi untuk menanam pohon kapas. Dengan benefit dan kenyamanan yang didapatkan konsumen pada Fast Fashion, dampak buruknya menjadi tidak dipedulikan. Slow Fashion bahkan bukan pilihan lagi bagi masyarakat yang sudah terpengaruh dengan fashion consumerism. Akibatnya Slow Fashion makin ditinggalkan, dan salah satu produk dari Slow Fashion adalah; Fashion Nusantara. Lantas dibutuhkan penanganan terhadap budaya fashion yang tidak sehat dengan mengambil pendekatan lokal, mengangkat nilai warisan budaya, sehingga tercipta budaya fashion yang sehat pada masa depan.
\end{abstract}

Kata kunci: pakaian; slow fashion; fast fashion; budaya

\begin{abstract}
Clothing or Fashion is a part of 3 primary human needs which are a requirement for survival. Initially, clothing is an object that is produced to fulfill a human need; produced in a sustainable, eco-friendly, ethical, and green manner. And this phenomenon is called Slow Fashion. But along with the development of the world regarding speed and acceleration (Dromology), in the world of fashion a new phenomenon arises, namely Fast Fashion. Fast Fashion, a mass production of disposable clothes with low prices and quality. This phenomenon changes consumerism in the fashion industry, where at low prices, consumers can keep abreast of trends and buy clothes for just a hobby. And as a result, these two phenomenon develop mutually and have a big impact on the condition of our ecosystem now; ranging from water pollution resulting from production waste, consumption of clean water in very large quantities, the accumulation of waste from old clothes, to deforestation to plant cotton trees. With the benefits and convenience that consumers get from Fast Fashion, the bad effects are ignored. Slow Fashion is not even an option anymore for people who have been influenced by fashion consumerism. As a result, Slow Fashion is increasingly being abandoned, and one of the products from Slow Fashion is; Nusantara Fashion. Then it takes the handling of an unhealthy fashion culture by taking a local approach, lifting cultural heritage values, so as to create a healthy fashion culture in the future.
\end{abstract}

Keywords: fashion; slow fashion; fast fashion; culture 


\section{PENDAHULUAN}

\section{Latar Belakang}

Pakaian atau Fashion merupakan sebuah bagian dari 3 kebutuhan primer manusia yang merupakan sebuah syarat untuk bertahan hidup. Pada awalnya sebuah fashion merupakan sebuah kebutuhan, dibuat seluruhnya dari material yang berkelanjutan dan sepenuhnya berasal dari alam. Sistem produksi yang etis dan green merupakan sebuah prinsip sebuah sandang, yang merupakan sebuah fenomena, The Slow Fashion. Slow Fashion menganjurkan manufaktur yang terkait dengan manusia, lingkungan, dan hewan serta melibatkan pengrajin lokal, dengan tujuan melestarikan kerajinan dan lingkungan dan, pada akhirnya, memberikan nilai bagi konsumen dan produsen.

Dromologi oleh Paul Virilio (1986) mengajarkan tentang bagaimana prinsip kecepatan dan percepatan dunia telah mengakar dalam kehidupan profesional, pribadi individu dan masyarakat dalam arti baik dan buruk, bagaimana hal itu berubah dan akan terus mengubah standar, nilai, persepsi dan mentalitas manusia.

Dunia tentang kecepatan dan percepatan ini pun memunculkan sebuah fenomena pada dunia fashion; Fast Fashion, sebuah produksi massal pakaian dengan harga murah dan kualitas sekali pakai. Fenomena ini mengubah consumerism dalam fashion industry, dimana dengan harga yang murah, konsumen dapat terus mengikuti perkembangan trend, serta membeli pakaian untuk hanya sekedar hobi.

Dan hasilnya kedua fenomena tersebut saling berkembang secara mutual dan memberikan dampak besar terhadap kondisi ekosistem kita sekarang; mulai dari polusi air yang dihasilkan dari limbah produksi, konsumsi air bersih dalam jumlah yang sangat besar, akumulasi limbah pakaian yang sudah tidak terpakai, hingga deforestasi untuk menanam pohon kapas. Dibalik itu semua, tenaga kerja dalam memproduksi pakaian pun merupakan sisi gelap dari dunia fashion. Perusahaan-perusahaan ini tidak bertanggung jawab atas kondisi kerja pabrik. Mereka cenderung pergi ke mana negara tidak menjunjung tinggi regulasi. Mereka membandingkan manufaktur murah dengan manufaktur murah untuk mendapatkan harga terbaik.

Dengan benefit dan kenyamanan yang didapatkan konsumen pada Fast Fashion, dampak buruknya menjadi tidak dipedulikan. Slow Fashion bahkan bukan pilihan lagi bagi masyarakat yang sudah terpengaruh dengan fashion consumerism. Akibatnya Slow Fashion makin ditinggalkan, dan salah satu produk dari Slow Fashion adalah; Fashion Nusantara. Dengan kondisi dunia yang mengutamakan kecepatan dan percepatan, mampukah Fashion Nusantara yang merupakan bagian dari Slow Fashion bertahan ?

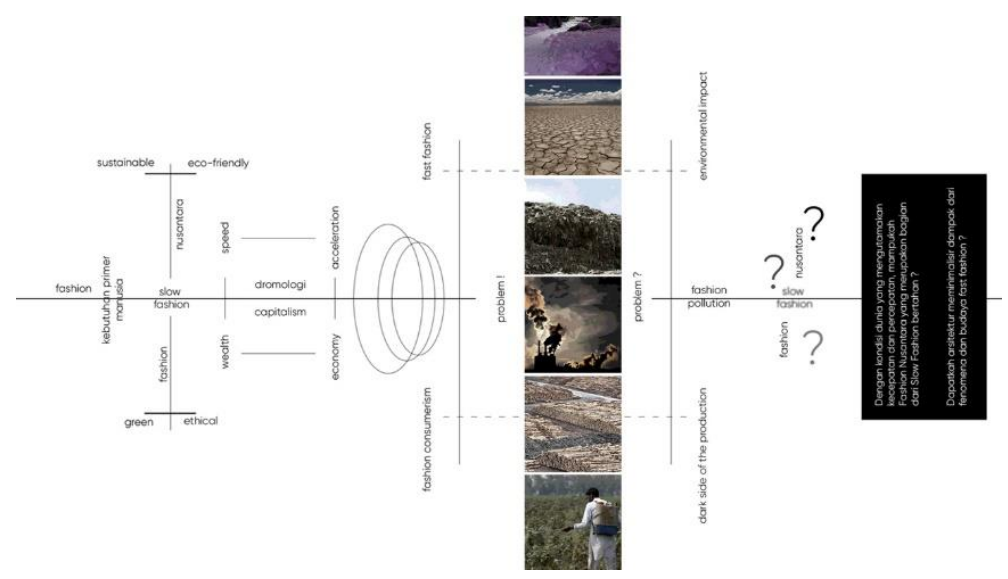

Gambar 1.Diagram Berfikir

Sumber : Data Pribadi,2021 


\section{Rumusan Permasalahan}

a. Dengan kondisi dunia yang mengutamakan kecepatan dan percepatan, mampukah fashion nusantara yang merupakan bagian dari slow fashion bertahan ?

b. Dapatkah arsitektur meminimalisir dampak dari fenomena dan budaya fast fashion ?

\section{Tujuan}

Menciptakan sebuah kondisi dimana Fashion Nusantara, yang merupakan bagian dari budaya Slow Fashion dan warisan budaya dapat bertahan pada dunia dromologi tentang kecepatan dan percepatan. Dengan bertahannya budaya Slow Fashion dan warisan budaya kita, maka dapat tercipta budaya fashion untuk masa depan yang sustainable, eco-friendly, ethical, dan green.

\section{KAJIAN LITERATUR}

\section{Fashion}

Definisi Fashion

Fashion berasal dari bahasa Latin, factio, yang artinya membuat atau melakukan.Karena itu, arti kata asli fashion mengacu pada kegiatan; fashion merupakan sesuatu yang dilakukan seseorang, tidak seperti dewasa ini, yang memaknai fashion sebagai sesuatu yang dikenakan seseorang. Arti dari kata fashion itu sendiri memiliki banyak sisi. Menurut Troxell dan Stone dalam bukunya Fashion Merchandising, fashion didefinisikan sebagai gaya yang diterima dan digunakan oleh mayoritas anggota sebuah kelompok dalam satu waktu tertentu.

Menurut Solomon dalam bukunya 'Consumer Behaviour: European Perspective', fashion adalah proses penyebaran sosial (social-diffusion) dimana sebuah gaya baru diadopsi oleh kelompok konsumen. "Fashion terutama busana, merupakan sisi kehidupan masyarakat yang saat ini sedemikian penting sebagai salah satu indikator bagi muncul dan berkembangnya gaya hidup (life style)" (Featherstone, 2001: 197).

Industri fashion memiliki dampak yang menghancurkan ekosistem lingkungan. Faktanya, ini adalah pencemar terbesar kedua di dunia, setelah industri minyak. Dan kerusakan lingkungan meningkat seiring pertumbuhan industri.

Penurunan harga pakaian selama 20 tahun terakhir telah memungkinkan kita untuk membeli lebih banyak pakaian. Kita sekarang memiliki pakaian 5 kali lebih banyak dari yang dimiliki kakek nenek kita. Pada kenyataannya, akumulasi pakaian murah yang berkelanjutan ini hanya mungkin terjadi karena penurunan biaya produksi yang konstan. Hal ini, berdampak serius pada kesehatan kita, ekosistem planet kita, dan kehidupan pekerja produksi pakaian.

\section{Fast Fashion}

Fashion didefinisikan sebagai ekspresi yang diterima secara luas oleh sekelompok orang dari waktu kewaktu dan telah dicirikan oleh beberapa faktor pemasaran seperti prediktabilitas rendah, pembelian impulsif tinggi, siklus hidup yang lebih pendek, dan volatilitas permintaan pasar yang tinggi (Fernie andSparks 1998). Dengan demikian, agar dapat menguntungkan dalam industri, produsen pakaian mode perlu mengambil pendekatan "speed to market" untuk memanfaatkan mode yang tidak ada di produsen pesaing mereka. Lebih jauh ditekankan bahwa ketanggapan dan ketangkasan pasar melaluipenggabungan cepat preferensi konsumen ke dalam proses desain dalam pengembangan produk meningkatkan margin keuntungan bagi produsen (Christopher, Lowson, dan Peck 2004). Konsumen menjadi lebih menuntut dan pengertian tentang fashion yang memaksa retailer fashion untuk menyediakan produk yang tepat pada waktu yang tepat di pasar - dengan kata lain, menyediakan fastfashion (cepat) (The Economist 2005). Informasi dan tren bergerak di seluruh dunia dengan kecepatanyang luar biasa, sehingga konsumen dapat memiliki lebih banyak pilihan dan dengan demikian 
berbelanja lebih sering (Hoffman 2007). Perubahan gaya hidup karena faktor sosiokultural dan kebutuhan akan keunikan memaksa produsen fashion untuk memperbaharui barang produksi secara konstan untuk menghadapi persaingan yang berkembang di pasar (Sproles and Burns 1994). Permintaan yang konstan dan bervariasi oleh konsumen telah memengaruhi proses peramalan dan pergeseran perencanaan produk; untuk mereplikasi desain dan gaya terkenal dari majalah mode dan peragaan busana dalam jumlah kecil lebih sering (Christopher, Lowson, dan Peck 2004).

\section{Slow Fashion}

Slow Fashion adalah konsep yang relatif baru yang dijelaskan oleh Kate Fletcher pada tahun 2007. KateFletcher menyatakan bahwa 'Konsep Slow Fashion banyak meminjam dari Slow Food Movement. Slow Food menghubungkan kesenangan dan makanan dengan kesadaran dan tanggung jawab. Sanjukta Pookulangara dan Arlesa Shephard melangkah lebih jauh dan berpendapat bahwa Slow Fashion 'didasarkan pada keberlanjutan dalam industri mode dan desain yang menggabungkan kualitas tinggi, garis-garis kecil, produksi regional, dan kondisi tenaga kerja yang adil,' lebih lanjut menjelaskan bahwa 'tujuan Slow Fashion bukanlah untuk benar-benar memperlambat rantai pasokantekstil dan pakaian jadi, tetapi lebih menekankan secara holistik untuk menciptakan proses yang lebih berkelanjutan, yang mencakup perencanaan desain, sumber produksi, dan pendidikan konsumen.

Ide di balik Slow Fashion adalah untuk mengurangi Fashion Consumerism dengan memberikan preferensi lebih pada lingkungan. Dari gaya hingga desain, kualitas hingga tujuan di balik pembuatannya, semuanya dipertimbangkan dalam Slow Fashion.

Berdasarkan tiga prinsip Slow Design yang diciptakan pada tahun 2006 di Milan, Hazel Clark, dalam SLOW + FASHION - an Oxymoron - atau a Promise for the future...? memutuskan untuk mendefinisikan prinsip-prinsip Gerakan Mode Lambat; mengambil pendekatan lokal, memiliki sistem produksi yang transparan, membuat produk yang berkelanjutan dan sensoris, tidak seperti Fast Fashion, Slow Fashion memastikan produksi berkualitas untuk memperpanjang umur pakaian. Mengembangkan pakaian dengan hubungan budaya dan emosional, juga berkaitan dengan tujuan di balik Slow Fashion; konsumen akan menyimpan pakaian lebih dari satu musim jika mereka merasa secara emosional atau budaya terhubung dengan artikel pakaian. Peraturan sedang dalam tahap awal pengembangan untuk mencegah perusahaan mode membeli atau memproduksi bahan yang tidak dibuat dengan bahan daur ulang, organik, atau digunakan kembali. Memanfaatkan bahan yang sudah dibuat akan mengurangi jejak karbon industri.

\section{Dromologi}

Dromologi berasal bahasa dari Yunani dromos, berarti race atau race-course. Dromologi, kemudian, adalah sebuah tubuh pengetahuan yang bersangkutan secara khusus dengan fenomena kecepatan, atau lebih tepatnya, dengan cara bagaimana kecepatan menentukan atau membatasi cara di mana fenomena muncul kepada kita. Paul Virilio adalah seorang teoritisi Perancis yang menciptakan suatu bentuk kajian yang inovatif dan membangkitkan minat yang pantas mendapat pengakuan luas. Kajiannya mengenai dromologi berasal dari akhiran "drome" yang merujuk pada jalur lomba lari atau tempat balapan mobil; dalam kajiannya, Virilio (1991a: 91) mengindikasikan minat utamanya pada "pentingnya kecepatan yang menentukan".

Pada tingkat yang lebih luas, Virilio tertarik mengenai hancurnya batas-batas yang disebabkan oleh perubahan teknologi yang kelewat dalam bentuk transportasi, komunikasi, telekomunikasi, komputerisasi, dan seterusnya. Bentuk awal perubahan ini 
menyebabkan perubahan atas susunan yang spasial, "distingsi di sini dan di sana tak lagi berarti apa-apa." Dengan kata lain, saat sekarang hal ini menimbulkan sedikit atau tidak ada perbedaan apakah seseorang tinggal di kota, pinggiran, atau daerah pedesaan. Sama halnya, apakah seseorang tinggal di Amerika Serikat, Inggris atau Jepang, bahkan Indonesia.

Lebih jauh, kebanyakan Virilio lebih tertarik dengan persoalan waktu daripada runag, karena waktu lebih penting daripada ruang di dunia postmodern. Kenyataannya dia menguraikan meningkatnya kecepatan menyebabkan terkikisnya distingsi parsial dan sangat sulit membedakan ruang dan waktu. Walhasil, pembuluh sinar Katoda, apakah ia dijumpai dalam televisi kita atau bersemayam dalam komputer kita, "dimensi spasial menjadi tidak dapat dipisahkan dari kecepatan transmisi" (Virilio, 1991a: 14). Dalam arti lain, ruang dan waktu makin tidak dapat dibedakan dari yang lain. Lebih jauh, kecepatan membanjiri jarak; "akselerasi dan pengurangan kecepatan, atau pergerakan dari pergerakan, ruang-dromospherik" (Virilio, 1991a: 102). Jadi, Virilio (1991a: 18) menciptakan prinsip "jarak kecepatan" dan menjelaskan bahwa ia menghancurkan fisik dan dimensi spasial. Saat ini yang paling penting adalah majunya sarana komunikasi dan telekomunikasi. Apa yang dihadapi masyarakat zaman modern ini merupakan sebuah krisis konseptualisasi dan representasi. Kecepatan dan cara dimana peningkatan kecepatan transmisi membentuk persepsi individu, tidak hanya kehidupan sosial, namun juga politik dan budaya. Kecepatan membuat manusia untuk terus bergerak atau memaksa untuk tidak diam, meskipun kita didalam pesawat kita terus bergerak. Kemajuan teknologi, baik di bidang transportasi, komunikasi, dan apa pun itu membuat manusia menghabiskan lebih banyak waktu dalam posisi inert atau stasioner.

Dalam mempermudah pemahaman kita mengenai teori dromologi ini, bisa kita lihat pada seseorang yang berwisata atau berpergian mengendarai suatu kendaraan, di mana keadaan tanah di depan seakan keadaannya lebih tinggi dari wisatawan tersebut, dan pemandangan yang berada di depan mobil akan terlihat bergantian sesuai giliran waktu yang paling terdekat, dari kejauhan seakan animasi yang sudah pasti akan dihadapi. Segala sesuatu yang dilewati seakan datang dengan cepat dan tiba-tiba. Di sini berarti manusia dihadapkan pada situasi yang selalu bergerak (percepatan), sehingga manusia diharuskan untuk selalu bergerak dan mengikuti perkembangan yang ada, karena bila dilihat dari contoh di atas lagi, sesuatu yang terlewati begitu cepat, dan sesuatu yang datang tiba-tiba akan cepat hilang. Oleh karena itu, manusia tidak boleh diam agar tidak ketinggalan mendapatkan hal-hal baru yang cepat hilang. Teori percepatan ini membuat waktu seakan menembus semua batas kehidupan yang apabila waktu berhenti, maka kehidupan juga ikut berhenti.

\section{METODE}

\section{Metode Perancangan}

Proses perancangan diawali dengan studi terhadap pendekatan isu yang diangkat dalam proyek ini yaitu tentang dromologi, fashion, dan hubungannya dengan ekologi bumi kita, dan juga sejumlah teori yang relevan untuk diterjemahkan menjadi proyek arsitektur dengan visi dan tujuannya.

Perancangan dilanjutkan dengan terciptanya visi dan konsep awal yang merespon terhadap isu yang diangkat dan dalam bahasa arsitektur. Dengan menciptakan kesadaran publik akan adanya isu dan fakta bahwa pakaian yang kita lihat dan pakai sehari-hari ternyata dapat menciptakan bencana terhadap ekosistem bumi kita. Hal tersebut ditransformasikan menjadi sebuah kualitas ruang dan spasial yang merespon tentang isu dromologi, fashion, dan kaitannya dengan ekologi bumi kita. 


\section{DISKUSI DAN HASIL}

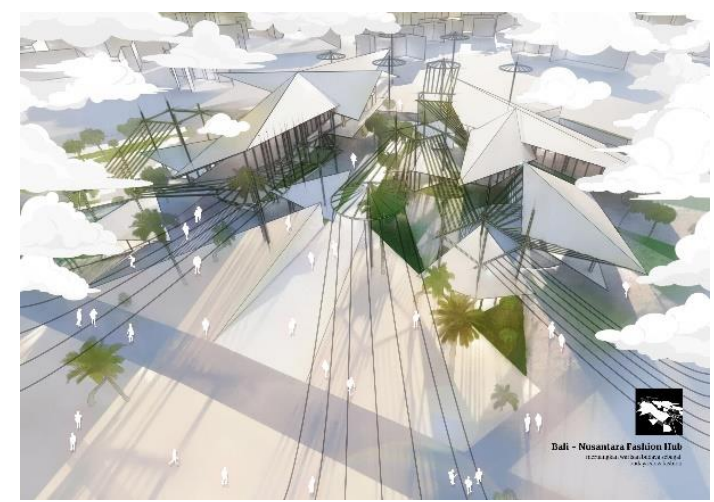

Gambar 2. Aerial Perspective Sumber : Data Pribadi,2021

Isu tentang Fashion dan ekologi merupakan ide utama dari proyek ini. Isu tentang bagaimana kultur fashion mulai berdampak buruk terhadap ekosistem bumi kita. Hal ini sebenarnya berjalan seiring dengan waktu, disebabkan oleh dromologi, timbul Fenomena Fast Fashion dengan harga yang murah, produksi cepat dan mengikuti zaman mode yang bergerak cepat. Hal ini terus berjalan hingga orang awam merasa nyaman dan tidak mempedulikan dampak buruknya; bahkan banyak yang tidak tahu dan sadar terhadap isu ini.

Pada Bali - Nusantara Fashion Hub, visi yang ingin dituju adalah; Menciptakan sebuah kondisi dimana Fashion Nusantara, yang merupakan bagian dari budaya Slow Fashion dan warisan budaya dapat bertahan pada dunia dromologi tentang kecepatan dan percepatan. Dengan bertahannya budaya Slow Fashion dan warisan budaya kita, maka dapat tercipta budaya fashion untuk masa depan yang sustainable, eco-friendly, ethical, dan green.

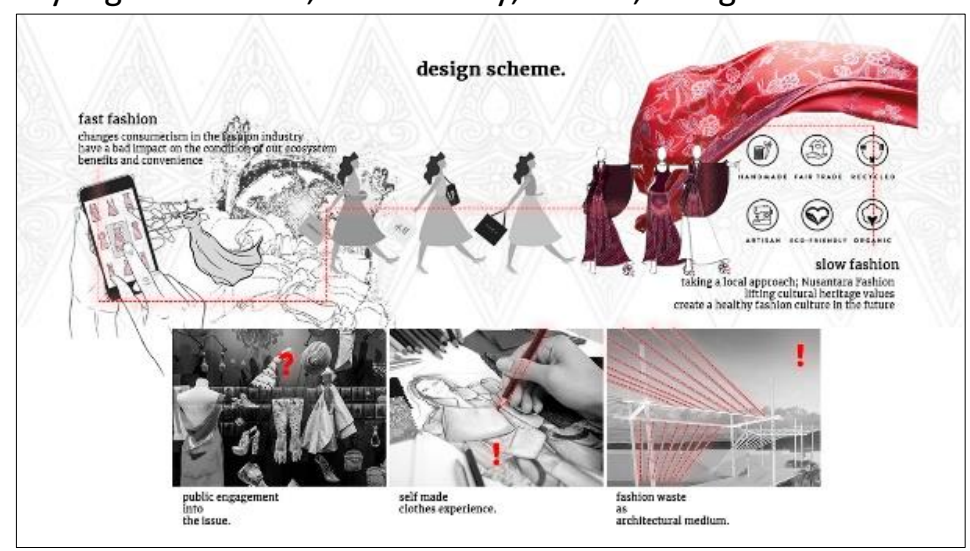

Gambar 3. Design Scheme

Sumber : Data Pribadi,2021

Untuk mencapai visi itu, Bali - Nusantara Fashion Hub memfokuskan pada 3 titik;

a. Menciptakan kedekatan publik pada isu dengan mengadakan fashion nusantara exhibition,

b. Selfmade clothes experience atau mewadahi para turis untuk membuat fashion yang sesuai dan tidak menghancurkan ekosistem bumi kita,

c. serta mengolah limbah fashion menjadi architectural medium pada Bali - Nusantara Fashion Hub untuk memperkuat kesan tema fashion pada bangunan.

Hal ini dilakukan sebagai penanganan terhadap budaya fashion yang tidak sehat dengan mengambil pendekatan lokal, mengangkat nilai warisan budaya, sehingga tercipta budaya fashion yang sehat pada masa depan. 


\section{Analisis Lokasi}

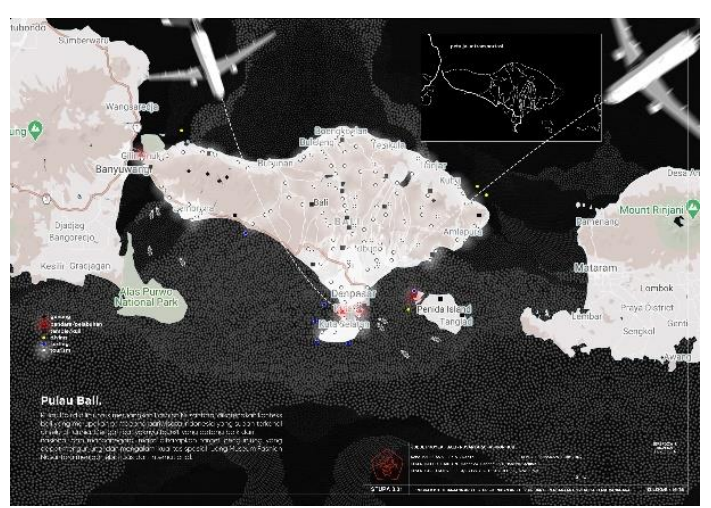

Gambar 4. Mapping Pulau Bali

Sumber : Data Pribadi,2021

Pulau Bali dipilih untuk meruangkan Fashion Nusantara, dikarenakan konteks bali yang merupakan primadona pariwisata Indonesia yang sudah terkenal di seluruh dunia. Dengan banyaknya tourist yang datang baik dari nasional dan mancanegara, maka diharapkan target pengunjung yang dapat mengunjungi dan mengalami kualitas spasial ruang Pusat Fashion Bali menjadi lebih luas dan international.

Tapak JI. Camplung Tanduk no 99, Seminyak, Kabupaten Badung, Bali. Site dipilih berdekatan dengan titik - titik tourism yang akan didatangi dan merupakan akomodasi bagi para turis baik lokal maupun internasional. Pendekatan ini dilakukkan agar tercipta Symbiosis kultur antara turis yang datang dan budaya nusantara, sehingga turis dapat mudah untuk datang dan mendapatkan berbagai pengetahuan serta persepsi tentang budaya fast fashion, fashion nusantara sebagai slow fashion secara penuh melalui kualitas spasial. Zona Tapak pada area tapak terbagi 2 zona ; Zona Resort + Hotel dan Zona Komersil

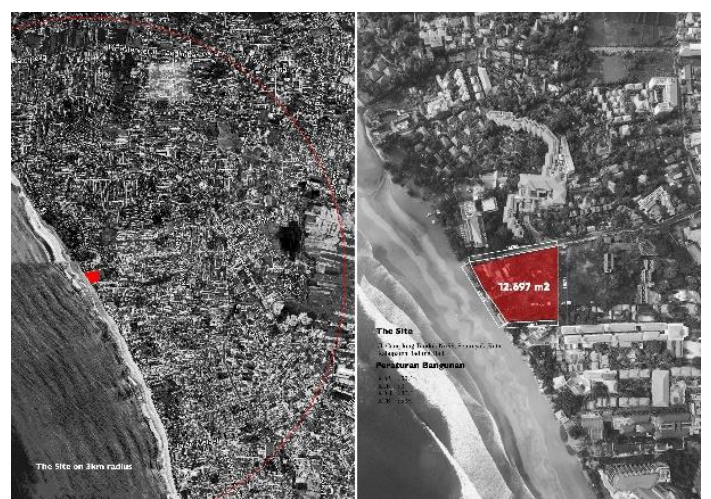

Gambar 5.Titik Lokasi, Sumber : Data Pribadi, Sumber : Data Pribadi,2021

\section{Urban Block}

Bangunan di dominasi oleh bangunan antara 2-4 lantai dengan berbagai bentukan massa yang menyesuaikan fungsi bangunan, mulai dari resort, restoran, kios, mall, dll.

\section{Fungsi}

Fungsi bangunan yang berada sekitar tapak hampir seluruhnya merupakan fungsi yang terkait dengan tourism ; mulai dari hotel, resort, commercial, hingga beachwalk

\section{Hierarki Jalan}

Jalan yang berada di sekitar tapak merupakan jalan kolektor yang merupakan jalan utama untuk kendaraan, serta jalan lokal untuk pedestrian berjalan kaki. 


\section{Neighborhood}

Neighborhood pada tapak antara lain merupakan sebuah resort, beachwalk, dan pada sisi depan tapak langsung bersentuhan dengan pantai yang merupakan unsur tourism yang unggul di Bali.

\section{Pencapaian}

Pencapaian ke tapak hanya memiliki 1 jalur untuk mobil, tetapi dengan sepeda motor dan berjalan kaki pencapaian dapat dilakukkan melalui beachwalk yang ada tepat di sisi barat tapak.

View

View pada tapak merupakan sebuah kekuatan pada tapak, mulai dari sisi barat yang langsung berhadapan dengan pantai, sisi kiri dan kanan yang bersebelahan dengan resort.

Fitur

Fitur pada tapak merupakan berdekatannya langsung dengan pantai / coastline yang merupakan keunikan dan keunggulan Pulau Bali. dan pada sisi lainnya merupakan jalur pencapaian ke tapak.

\section{Transformasi Massa}

Site Offset

Massa dibentuk dari tapak dan di offset sesuai peraturan yang berlaku

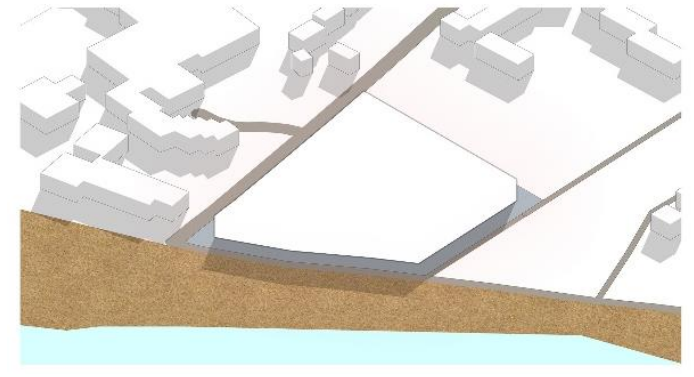

Gambar 6. Diagram Transformasi Massa I

Sumber : Data Pribadi, 2021

Axis Gunung Agung \& Laut Bali

Untuk menghormati axis Gunung Agung dan Latur Bali, maka massa bangunan dipotong sesuai axis.

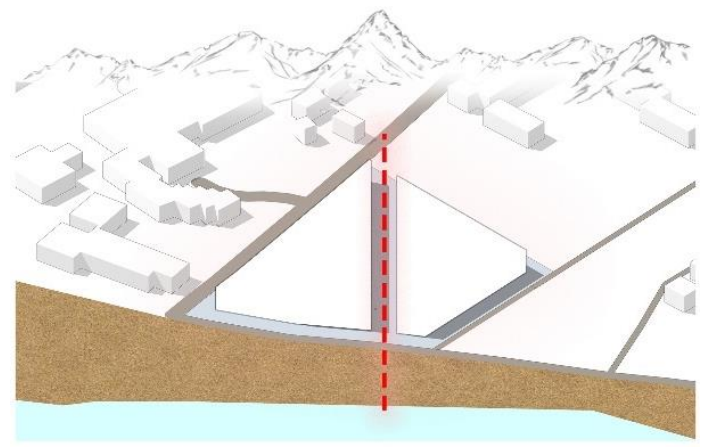

Gambar 7. Diagram Transformasi Massa II Sumber : Data Pribadi,2021

Akses \& Sirkulasi

Massa kembali dibelah dan di substract sesuai kebutuhan dan respon terhadap akses dan sirkulasi pada site dan lingkungan 


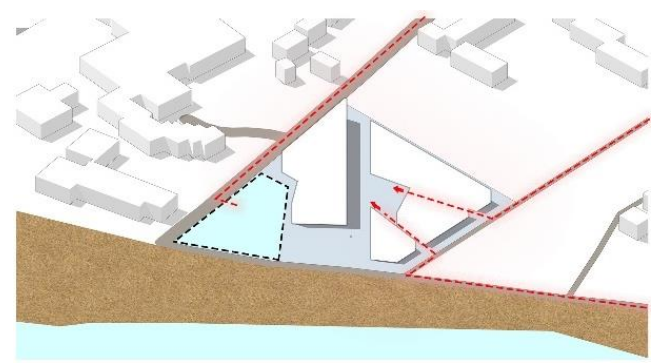

Gambar 8. Diagram Transformasi Massa III, Sumber : Data Pribadi,2021

Evolusi Bentuk \& Pendekatan Arsitektur Tropis

Evolusi bentuk massa sesuai dengan metode design geometry dan cartesian serta pendekatan arsitektur tropis.

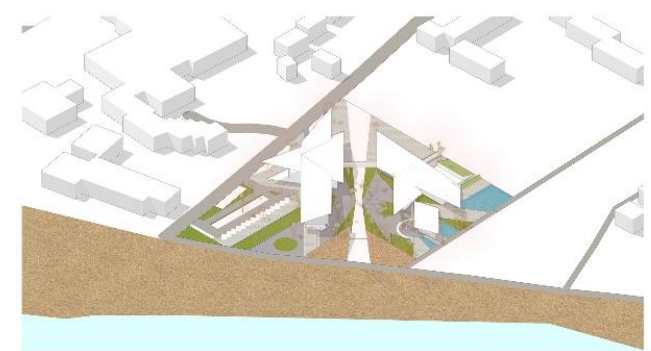

Gambar 9. Diagram Transformasi Massa IV Sumber : Data Pribadi,2021

\section{Penambahan Unsur Design dan Program}

Penambahan unit dan massa kecil sebagai unsur baru dan penunjang program utama pada tapak.

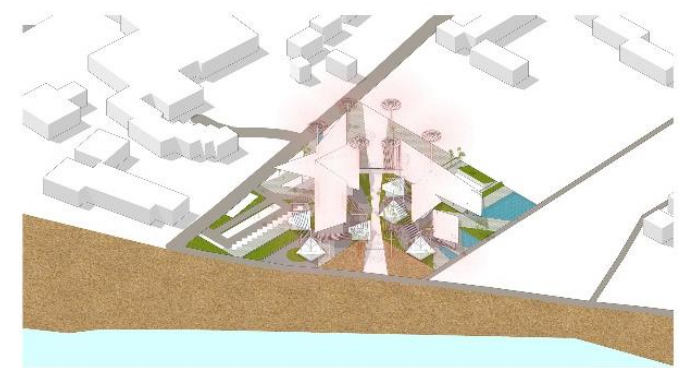

Gambar 10. Diagram Transformasi Massa V Sumber : Data Pribadi,2021

\section{Metode Design}

Pembentukan Geometri dari Karakteristik Fashion Nusantara.

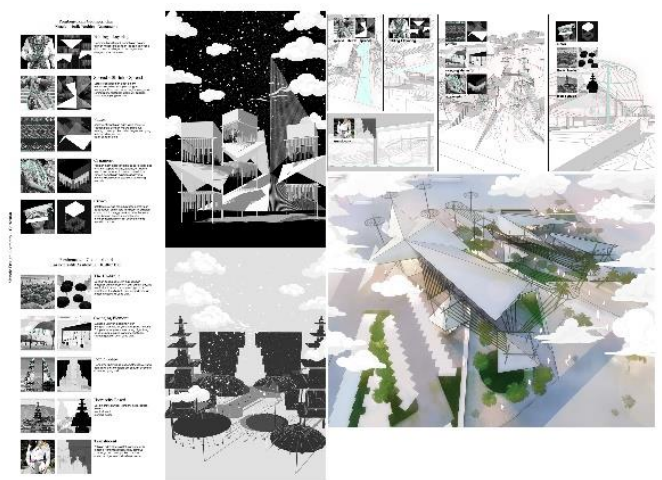

Gambar 11. Diagram Metode Design Sumber : Data Pribadi,2021 


\section{Folding \& Layering}

Geometri karakteristik pemakaian dalam fashion nusantara dengan lapisan kain yang dilipat secara diagonal dan tegak lurus dengan tubuh manusia.

\section{Spread - Shrink - Spread}

Karakteristik pakaian adat dalam menciptakan kesan "rapih" dengan menggunakkan belt pada bagian pinggang sehingga menciptakan geometri pakaian pada tubuh yang menarik.

\section{Pattern}

Karakteristik pakaian adat yang memiliki sebuah pola dengan makna sakralnya masing2, menciptakan sebuah geometri yang terbagi ; dengan pola tidak dengan pola.

\section{Ornament}

Pakaian adat tidak lengkap apabila tidak ada ornamen seperti kalung, gelang, dll. Hal ini menciptakan sebuah lapisan baru dalam konsep pemakaian pakaian adat yang menciptakan sebuah geometri baru yang menarik.

\section{Crown}

Seletah melewati seluruh proses pemakaian pada tubuh, Salah satu karakteristik pakaian adat adalah menggunakkan sebuah crown pada bagian kepala si pemakai dan diinterpretasikan menjadi geometri yang memiliki karakter.

Pembentukan Geometri dari Karakteristik Arsitektur \& Kultur Bali.

The Umbrella

Dengan cuaca dan iklim bali dengan matahari yang cukup terik dan panas, payung menjadi salah satu unsur penting dalam perjalanan turis ke bali, dan menjadi sebuah materi arsitektural yang unik.

\section{Swinging Element}

Suasana Bali yang berangin pun menghasilkan design yang unik pada Payung Bali yaitu adanya ornamen yang digantung pada ujung2 payung yang menciptakan sebuah gerakan ayun yang unik.

\section{Iconic Shape}

Mengambil bentuk dari geometri2 iconic yang berada di bali, menciptakan sebuah geometri dan unsur yang unik.

Hierarchy Based

Design arsitektur bali yang memiliki sebuah hierarki ; menjadi kecil, menjadi besar.

\section{Translucent}

Pakaian adat; Kebaya Bali yang memiliki material yang translucent atau tembus pandang, dan menciptakan karakter arsitektural yang unik dan berkarakter. 


\section{Programming}

\begin{tabular}{|c|c|c|c|c|}
\hline Jenis Ruang & Standard & Kapasitas & Sumber & Luas (m 2) \\
\hline \multicolumn{5}{|l|}{ EXHIBITION SPACE } \\
\hline Lobby & $0,5 \mathrm{~m} 2 /$ orang & 200 orang & NAD & 100 \\
\hline Loket & $15 \mathrm{~m} 2 /$ orang & 5 orang & NAD & 75 \\
\hline Ruang Antri & $1 \mathrm{~m} 2 /$ orang & 50 orang & A & 50 \\
\hline Ruang Informasi & $3,2 \mathrm{~m} 2$ / orang & 2 orang & NAD & 6,4 \\
\hline Permanent Them atic Slow Fashion Exhibition & $1000 \mathrm{~m} 2$ & 2 unit & A & 2000 \\
\hline Primary Fashion Nusantara Exhibition & $1000 \mathrm{~m} 2$ & 3 unit & A & 3000 \\
\hline \multicolumn{5}{|l|}{ EDUKASI + WORKSHOP } \\
\hline Ruang Konferensi & $300 \mathrm{~m} 2$ & 1unit & A & 300 \\
\hline Ruang Multifungsi & $300 \mathrm{~m} 2$ & 1unit & A & 300 \\
\hline Indoor Fashion Runway & $300 \mathrm{~m} 2$ & 1unit & A & 300 \\
\hline Ruang Penerimaan Limbah Fashion & $15 \mathrm{~m} 2 /$ orang & 2 orang & NAD & 30 \\
\hline Ruang Workshop Limbah Fashion & $150 \mathrm{~m} 2$ & 1unit & A & 150 \\
\hline Ruang Workshop Pembuatan Fashion & $150 \mathrm{~m} 2$ & 1unit & A & 150 \\
\hline Bali Vintage Shop & $150 \mathrm{~m} 2$ & 1unit & A & 150 \\
\hline Fashion Thrift Shop & $150 \mathrm{~m} 2$ & 1unit & A & 150 \\
\hline Recycled Fashion Waste Shop & $150 \mathrm{~m} 2$ & 1unit & A & 150 \\
\hline \multicolumn{5}{|l|}{ REGISTRASI + ADMINISTRASI + KONSERVASI } \\
\hline Ruang Registrasi Koleksi & $15 \mathrm{~m} 2 /$ orang & 2 orang & NAD & 30 \\
\hline Ruang Penyimnpanan Sementara & $150 \mathrm{~m} 2$ & 1unit & A & 150 \\
\hline Ruang Penyimpanan Tetap & $150 \mathrm{~m} 2$ & 1unit & A & 150 \\
\hline Ruang Konservasi & $150 \mathrm{~m} 2$ & 1unit & A & 150 \\
\hline Ruang Fumigasi & $150 \mathrm{~m} 2$ & 1unit & A & 150 \\
\hline Ruang Kepala Kurator & $10 \mathrm{~m} 2$ / orang & 1orang & NAD & 10 \\
\hline Ruang Administrasi & $4 \mathrm{~m} 2 /$ orang & 5 orang & NAD & 20 \\
\hline Ruang Kepala Keuangan & $2 \mathrm{~m} 2 /$ orang & 5 orang & NAD & 10 \\
\hline Ruang Staff Exhibition & $2 \mathrm{~m} 2 /$ orang & 20 orang & NAD & 40 \\
\hline Ruang Staff Education & $2 \mathrm{~m} 2 /$ orang & 20 orang & NAD & 40 \\
\hline Ruang Staff Workshop & $2 \mathrm{~m} 2 /$ orang & 10 orang & NAD & 20 \\
\hline Ruang Staff Shop & $2 \mathrm{~m} 2 /$ orang & 10 orang & NAD & 20 \\
\hline R. Meeting & $2 \mathrm{~m} 2 /$ orang & 20 orang & NAD & 40 \\
\hline Loker & $0,05 \mathrm{~m} 2 /$ orang & 100 orang & A & 50 \\
\hline \multicolumn{5}{|l|}{ PROGRAM PENUNJANG } \\
\hline Lobby Perpustakaan & $15 \mathrm{~m} 2 /$ orang & 3 orang & NAD & 45 \\
\hline Area Baca Perpustakaan & $60 \mathrm{~m} 2$ & 1unit & NAD & 60 \\
\hline Ruang Staff Perpustakaan & $2 \mathrm{~m} 2 /$ orang & 5 orang & NAD & 10 \\
\hline Restaurant & $200 \mathrm{~m} 2$ & 2 unit & A & 400 \\
\hline Café & $100 \mathrm{~m} 2$ & 1unit & A & 100 \\
\hline \multicolumn{5}{|l|}{ KEAMANAN } \\
\hline Ruang CCTV & $16 \mathrm{~m} 2$ & 1unit & SRG & 16 \\
\hline Ruang Keamanan & $8 \mathrm{~m} 2$ & 1unit & SRG & 8 \\
\hline \multicolumn{5}{|l|}{ LAVATORY } \\
\hline Lavatory Pria 6 unit & $\begin{array}{l}\text { Wc } 1,2 \mathrm{~m} 2 \text { / unit, } \\
\text { Urinal 0,6 m2 / unit, } \\
\text { Wastafel } 1,2 \mathrm{~m} 2 \text { / } \\
\text { unit }\end{array}$ & $\begin{array}{l}3 \text { wc - } 3 \text { urinal - } \\
2 \text { wastafel }\end{array}$ & A & 40,8 \\
\hline Lavatory Wanita 6 unit & $\begin{array}{l}\text { Wc } 12 \mathrm{~m} 2 / \text { unit, } \\
\text { Wastafel } 12 \mathrm{~m} 2 / \\
\text { unit }\end{array}$ & 4 wc -3 wastafe & A & 44,4 \\
\hline \multicolumn{5}{|l|}{ SERVIS } \\
\hline Gudang & $15 \mathrm{~m} 2$ & 1unit & A & 15 \\
\hline Ruang Staff Perawatan & $4,8 \mathrm{~m} 2 /$ orang & 4 orang & SRG & 19,2 \\
\hline Ruang PABX & $12 \mathrm{~m} 2$ & 1unit & SRG & 12 \\
\hline Ruang Genset & $250 \mathrm{~m} 3$ & 1unit & SRG & 72 \\
\hline Ruang Panel Control & $10 \mathrm{~m} 2$ & 1unit & SRG & 10 \\
\hline Ruang Pompa & $500 \mathrm{~m} 3$ & 1unit & SRG & 30 \\
\hline Ruang Reservoir & $125 \mathrm{~m} 3$ & 1unit & SRG & 56,4 \\
\hline Loading Dock & $40 \mathrm{~m} 2$ & 1unit & A & 40 \\
\hline & & & & 8770,2 \\
\hline SIRKULASI $20 \%$ & & & & 1754,04 \\
\hline TOTAL & & & & 10524,24 \\
\hline
\end{tabular}




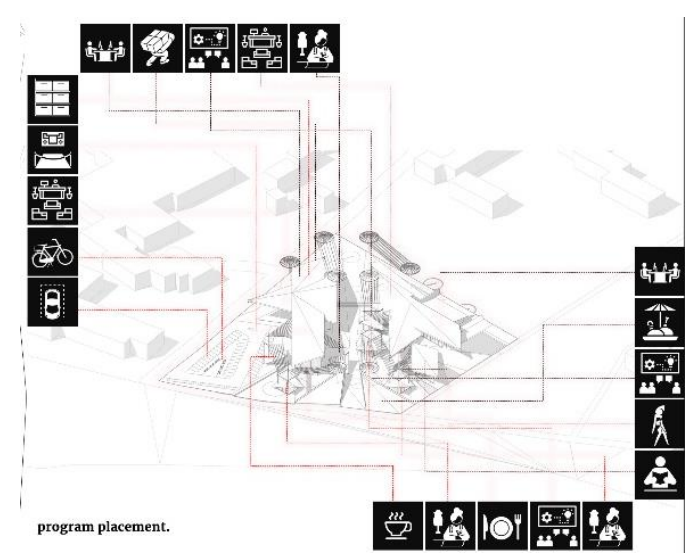

Gambar 12. Diagram Program Placement Sumber : Data Pribadi,2021

Penempatan program dan kegiatan pada massa bangunan yang disesuaikan dengan design dan alur pengunjung dalam merasakan kualitas spasial setiap program yang ada.

\section{Perspektif Bangunan}

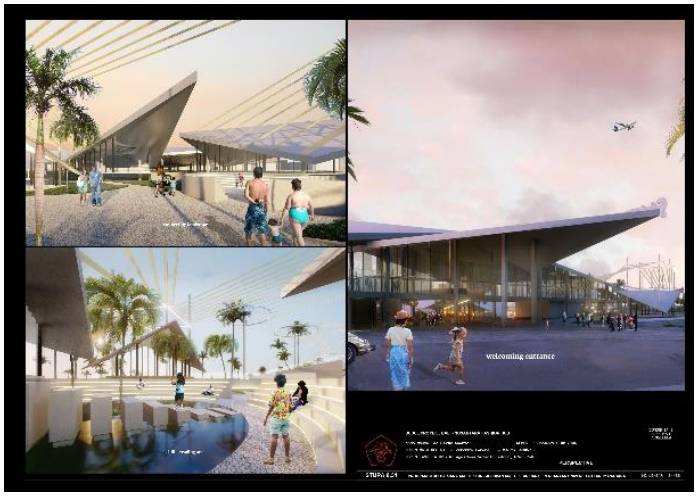

Gambar 13. Perspective I

Sumber : Data Pribadi,2021

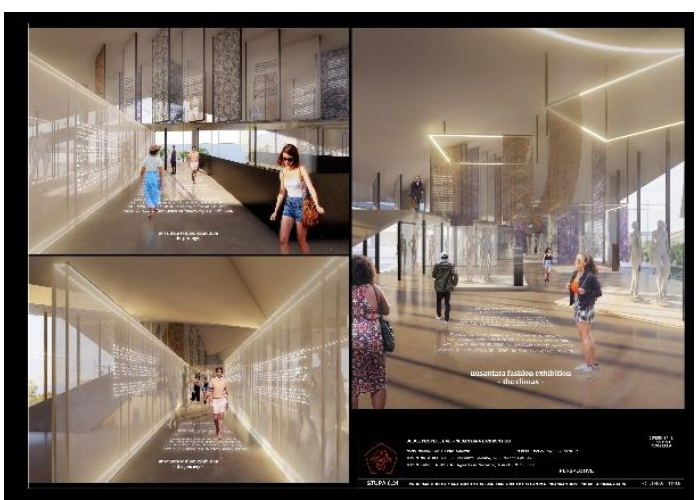

Gambar 14. Perspective II

Sumber : Data Pribadi,2021 


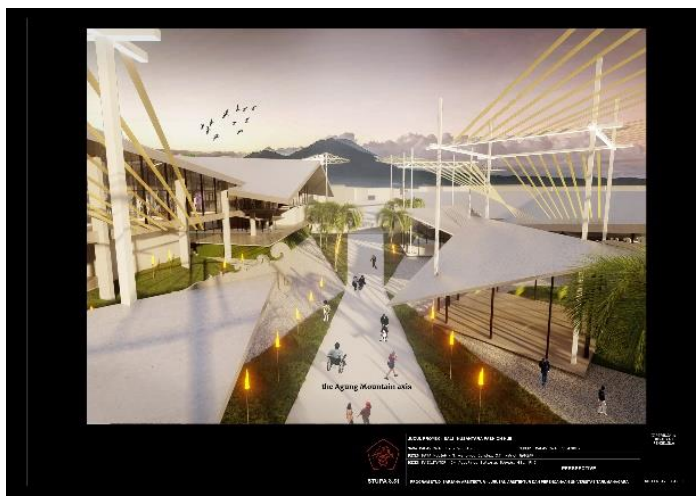

Gambar 15. Perspective III

Sumber : Data Pribadi,2021

Perspektif bangunan yang memperlihatkan bagaimana suasana site, kualitas spasial serta program pada bangunan.

\section{KESIMPULAN DAN SARAN Kesimpulan}

Untuk mencapai visi yang dituju, yaitu budaya dan kultur fashion untuk masa depan yang sustainable, eco-friendly, ethical, dan green, diperlukan sebuah partisipasi dari masyarakat luas. Bali - Nusantara Fashion Hub memiliki 3 unsur penting untuk mencapai visi tersebut ; menciptakan public engagement pada isu ini dengan mengadakan fashion nusantara exhibition, selfmade clothes experience atau mewadahi para turis untuk membuat fashion yang sesuai dan tidak menghancurkan ekosistem bumi kita, serta mengolah limbah fashion menjadi architectural medium pada Bali - Nusantara Fashion Hub untuk memperkuat kesan tema fashion pada bangunan. Bali - Nusantara Fashion Hub dilengkapi dengan program-program utama yang merespon isu tersebut; nusantara fashion exhibition, fashion runway, beberapa ruang workshop tentang fashion, serta restaurant, café sebagai program penunjang.

\section{Saran}

Dalam perancangan yang memiliki tujuan dan visi tentang budaya dan budaya fashion, perlu diperhatikan beberapa aspek tentang bagaimana menciptakan public engagement terhadap isu fashion dan kulturnya. Selain itu perlu diperhatikan tentang konteks pada site dikarenakan berhubungan tentang target pengunjung dan seberapa dalam masyarakat akan sadar terhadap isu tersebut.

\section{REFERENSI}

Badan Pusat Statistik Provinsi Bali. (2020). PROVINSI BALI DALAM ANGKA 2020.

Christopher, M., R. Lowson, and H. Peck. (2004). Creating agile supply chains in the fashion industry.International Journal of Retail and Distribution Management32.

Featherstone, M. (2007). "Slow fashion movement: Understanding consumer perceptions-An exploratory study." Journal of Retailing and Consumer Services; Amsterdam, Netherlands Fernie, J., and L. Sparks. (1998).Logistics and retail management, insights into current practiceand trends from leading experts. London: Kogan Page.

Greenpop (2019).Conscious consumerism: Fast fashion fuelling fashion failure? https://greenpop.org/conscious-consumerism-fast-fashion-fuelling-fashion-failure/

Purpose Up. The True Cost Documentary: Fast Fashion \& Consumption's Darkside. https://www.purposeup.com/true-cost-fast-fashion-darkside/ 
Sustain Your Style. What's wrong with the fashion industry. https://www.sustainyourstyle.org/old-whats-wrong-with-fashion-

The Economist. (2005). The future of fast fashion: Inditex.The Economist. Virilio, P. 1991. The Aesthetics of Disappearance., trans. M. Polizzotti, New York: Semiotext(e).

Thomas Hauer (November 2014). Speed and Slowness: Dromology and Technical Images. https://www.hilarispublisher.com/open-access/speed-and-slowness-21516200.100082.pdf

Thomas Hauer (November 2015). Dromologic Revolution and Dromospheric Chronology. https://www.hilarispublisher.com/open-access/dromologic-revolution-anddromosphericchronology-2151-6200-1000136.pdf

Trisnawati, T.Y. (2011). Fashion sebagai Bentuk Ekspresi Diri dalam Komunikasi. Jurnal The Messenger; Indonesia

United Nations. THE 17 GOALS : SUSTAINABLE DEVELOPMENT GOALS. https://sdgs.un.org/goals Vertica B. and Ann Fairhurst. (2009). Fast fashion: response to changes in the fashion industry. Wibisono. T, Rizky. R . (2015). Mengenal Seni dan Budaya 34 Provinsi di Indonesia. 